Published in final edited form as:

Exp Gerontol. 2007 October ; 42(10): 931-938.

\title{
Age-Related Decline in Actomyosin Structure and Function
}

\author{
Ewa Prochniewicz ${ }^{1}$, LaDora V. Thompson ${ }^{2}$, and David D. Thomas ${ }^{1}$ \\ 1 Department of Biochemistry, Molecular Biology and Biophysics, University of Minnesota, Minneapolis MN \\ 55455 \\ 2Department of Physical Medicine and Rehabilitation, University of Minnesota, Minneapolis MN 55455
}

\begin{abstract}
This review focuses on the role of changes in the contractile proteins actin and myosin in age-related deterioration of skeletal muscle function. Functional and structural changes in contractile proteins have been determined indirectly from specific force and unloaded shortening velocity of permeabilized muscle fibers, and were detected directly from site-directed spectroscopy in muscle fibers and from biochemical analysis of purified actin and myosin. Contractile proteins from aged and young muscle differ in (a) myosin and actomyosin ATPase activities, (b) structural states of myosin in contracting muscle, (c) the state of oxidative modifications. The extent of age-related physiological and molecular changes is dependent on the studied animal, the animal's age, and the type of muscle. Therefore, understanding the aging process requires systematic, multidisciplinary studies on physiological, biochemical, structural, and chemical changes in specific muscles.
\end{abstract}

\section{Keywords}

actin; myosin; aged muscle; enzymatic activity; oxidative modifications

\section{Introduction}

Aging is associated with a progressive loss of muscle mass, slowing of muscle movement, and decline in muscle strength. The mechanisms of age-related deterioration of contractility involve multiple factors associated with changes in the process of muscle excitation, regulation, and molecular interactions. This review is focused on age-related changes in the interaction between the contractile proteins actin and myosin.

\section{Age-related changes in the contractility of permeabilized muscle}

Physiological studies have detected age-related deterioration of muscle contractility in both intact and permeabilized muscle; the latter, which lacks the membrane-bound excitationcontraction coupling system and soluble proteins involved in energy metabolism, offers more direct information on contractile proteins. Studies on permeabilized muscle from several strains of rats (Fischer 344 Brown Norway F1 Hybrid, Wistar and Fischer 344) showed that the two principal contractile parameters, specific force $\left(\mathrm{P}_{0}\right.$, force divided by cross-sectional area) and unloaded shortening velocity $\left(\mathrm{V}_{0}\right)$, generally decrease progressively with the animal's age. Examples of results, provided in Table 1, show that the extent of changes is variable, depending

Corresponding author: Ewa Prochniewicz, Department of Biochemistry, Molecular Biology and Biophysics, University of Minnesota, Jackson Hall 6-155, 321 Church St. Minneapolis, MN 55455. email: ewa@ ddt.biochem.umn.edu T: (612) 626-3344; F: (612) 624-0632

Publisher's Disclaimer: This is a PDF file of an unedited manuscript that has been accepted for publication. As a service to our customers we are providing this early version of the manuscript. The manuscript will undergo copyediting, typesetting, and review of the resulting proof before it is published in its final citable form. Please note that during the production process errors may be discovered which could affect the content, and all legal disclaimers that apply to the journal pertain. 
on the muscle and age of animals. Age-related decline in contractility was systematically observed in soleus and semimembranosus muscle from rats and vastus lateralis muscle from aging human volunteers, but no significant age-related changes were reported for EDL muscle of several strains of rats. Age-related changes in EDL could occur at a much slower rate than in other muscles, but this possibility remains to be tested in studies using much older animals.

Observed age-related decline of contractility in permeabilized muscle indicates age-related changes in the interaction between muscle actin and/or myosin, which make 18\% to $22 \%$ (actin) and 43\% to 50\% (myosin) of its total protein content (Yates and Greaser, 1983; Ingalls, Warren et al., 1998). However, since the interaction between actin and myosin in the muscle filament lattice also depends on other structural and regulatory proteins, a more direct assessment of this conclusion requires specific measurements of biochemical and structural properties of actin and myosin from young and aged muscle.

\section{Brief review of muscle structure and molecular basis of contractility}

The basic contractile unit of muscle, the myofibril, consists of a linear array of sarcomeres, and each sarcomere contains interdigitating thick and thin filaments. The main components of the thick filament are myosin molecules aggregated vial their "tail" regions into a bipolar filament. The catalytic and force-generating function of myosin is located in its "head" region, which contains the catalytic domain (with sites for ATP hydrolysis and interaction with actin), and the light chain (LC) domain, which contains the essential (ELC) and regulatory (RLC) light chains. The main component of the thin filaments is a helical polymer of globular actin monomers, which contain specific sites of interaction with myosin. (Figure 1).

Interaction of the myosin head with actin in the presence of ATP (Figure 2) results in sliding of thin filaments past thick filaments toward the center of the sarcomere, contracting the sarcomere. The biochemical steps of ATP hydrolysis during this cyclic interaction of actin with myosin are accompanied by a sequence of structural transitions in both proteins. In the absence of ATP and/or the presence of ADP, the myosin head forms a strong and well-ordered complex with actin. Binding of ATP to myosin produces a weaker complex where the catalytic domain (blue) and light chain domain of myosin (green) are disordered. The release of phosphate $\left(\mathrm{P}_{\mathrm{i}}\right)$ from myosin causes a structural transition in the catalytic and light chain binding domains, generates force, and initiates a new cycle (Thomas, Prochniewicz et al., 2002;Prochniewicz, Walseth et al., 2004). Force can decline if the system spends too much time in the weak-binding states, or the strong-binding states are weakened. Velocity can decline if the system spends too much time in the strong-binding states. Thus, age-related structural or chemical changes in actin and myosin that affect actomyosin ATPase activity by affecting the weak-to-strong actomyosin transition are likely to change muscle function.

\section{Age-related changes in actomyosin ATPase activity}

Measurements of muscle ATPase activity is often performed on myofibrils (minced muscle fibers), which preserve the organization and interaction between actin and myosin in the muscle, while their uniform suspension enables quantitative determination of the protein concentration and specific enzymatic (ATPase) activity. Numerous biochemical studies established that myofibrillar ATPase activity at high $(0.6 \mathrm{M})$ salt concentration is quite sensitive to post-translational changes in myosin, particularly the covalent modification of specific cysteines and lysines, depending on the principal cation present $\left(\mathrm{Ca}^{++}\right.$or $\mathrm{K}^{+}$and on the affected sites and modifying reagents (Takashi, Duke et al., 1976;Reisler, 1982;Crowder and Cooke, 1984;Bertrand, Derancourt et al., 1995;Bobkov, Bobkova et al., 1997;Ajtai, Peyser et al., 1999;Bobkova, Bobkov et al., 1999). This property of high-salt ATPase activities of myofibrils and myosin from muscle of various strains of rats was used to assess age-related molecular changes in myosin (Table 2). 
Observed changes in the ATPase activities provided strong indication of age-related posttranslational modifications of myosin, but did not provide sufficient information to determine the sites or nature of modification, nor to predict the functional consequences.

Further progress in understanding the molecular basis of age-related deterioration of muscle contractility requires ATPase measurements made under more physiological conditions (i.e., less than $0.3 \mathrm{M}$ ionic strength, in the presence $\mathrm{MgCl}_{2}$ ) in myofibrils or in purified actin and myosin, which are directly associated with the $\mathrm{V}_{0}$ of muscle (Barany, 1967; Marston and Taylor, 1980). Despite their critical importance, published studies on age-related changes in myofibrillar or actomyosin ATPase activity under activating conditions are very limited. Early studies showed a gradual age-related decrease in the ATPase activity of actomyosin from mixed rat muscle, which was interpreted in terms of changes in the molecular properties of myosin, but no contractility data were reported in this study (Kaldor and Min, 1975). The only muscle in which both contractility and ATPase activity were measured under activating conditions, as a function of age, is semimembranosus muscle of Fischer 344 Brown Norway rats. Under isometric conditions, simultaneous measurement of force and ATPase activity in single fibers of aged (32-37 months) and young ( $8-12$ months) rats showed that aged fibers generated $\sim 20$ lower maximum force without changes in the ATPase activity (Lowe, Thomas et al., 2002). This result indicated a decrease in the energetic efficiency, a partial uncoupling between ATPase activity and force generation, during isometric contraction in aged muscle. Under unloaded shortening conditions in the same muscle, the same group reported that aging to 32 -38 months resulted in a $16 \%$ decrease in the myofibrillar ATPase activity and a similar decrease in the shortening velocity (Lowe, Husom et al., 2004). At its time, this report provided the most direct and detailed evidence that changing actin-myosin interactions contribute to age-related inhibition of contractility.

This conclusion obtained more direct and detailed support from biochemical experiments performed on actin and myosin isolated from the hamstring muscle of young (4-12 months) and aged (27-35 months) Fischer 344 rats (Prochniewicz, Thomas et al., 2005). These studies determined two key parameters of the actomyosin ATPase, $\mathrm{V}_{\max }$ (activity extrapolated to infinite actin concentration) and $\mathrm{K}_{\mathrm{m}}$ (the concentration of actin at half $\mathrm{V}_{\max }$ ) by performing measurements on the complex of actin and the catalytically active fragment of myosin, heavy meromyosin (HMM). The observed $21 \%$ decrease in $\mathrm{V}_{\max }$ and a $24 \%$ decrease in $\mathrm{K}_{\mathrm{m}}$ of actinactivated HMM ATPase (Prochniewicz, Thomas et al., 2005) (Figure 3) provided the most direct support for the role of changes in the contractile proteins in the deterioration of muscle function. Mixing of actin and myosin from young and old muscle in four combinations showed that the age-related decrease in $V_{\max }$ was primarily due to changes in myosin. This decrease in $\mathrm{V}_{\max }$ suggested age-related alterations in the structural states of myosin that affect the transitions from weak to strong interactions, such as disorder-to-order transitions in the catalytic and light-chain domains or changes in the internal structure of the catalytic domain (Figure 2) (Thomas, Prochniewicz et al., 2002). However, the age-related decrease in $\mathrm{K}_{\mathrm{m}}$ was due to changes in both proteins, as actin from young muscle attenuated the age-related decrease in $\mathrm{K}_{\mathrm{m}}$ for myosin from old muscle. The changes in $\mathrm{K}_{\mathrm{m}}$ are related to changes in the equilibria between actin and myosin-nucleotide complexes at the final stages of the cycle (Figure 2). This provided the first evidence that changes in actin, together with changes in myosin, are involved in the molecular mechanism of age-related deterioration of muscle contractility.

\section{Age-related changes in the functional properties of myosin and actin: in vitro motility}

The contractile properties of purified actin and myosin can be directly studied using the in vitro motility assay, a novel method for analyzing the interaction of actin and myosin at the single-molecule level. In this assay, isolated myosin molecules are immobilized on the glass 
surface, fluorescent actin filaments are added, and sliding movement of these filaments, initiated by addition of ATP, is directly observed under an optical microscope (Figure 4).

The in vitro motility assay performed on myosin from the human vastus lateralis muscle showed that the observed decrease of sliding speed of actin on myosin from aged muscle was comparable to the age-related decrease in the unloaded fiber shortening velocity $\mathrm{V}_{0}$ ( $\mathrm{D}^{\prime}$ 'Antona, Pellegrino et al., 2003), directly supporting the role of molecular changes in myosin in agerelated deterioration of this muscle's contractility. On the other hand, the $12 \%$ to $25 \%$ decrease of actin sliding speed on myosin isolated from aged soleus muscle (Wistar rats, C57B1/6 mice, and humans ) (Hook, Li et al., 1999;Hook, Sriramoju et al., 2001) was much less pronounced than the $47 \%$ decrease in $\mathrm{V}_{0}$, previously determined by the same laboratory for rat soleus muscle ( $\mathrm{Li}$ and Larsson, 1996). It was suggested that larger effects on fiber contractility than on the sliding velocity of actin filament in the in vitro motility reflect age-related changes in myosin as well as in the structural and thin filament proteins of muscle (Hook, Li et al., 1999;Hook, Sriramoju et al., 2001).

The quantitative differences between age-related changes in the enzymatic and contractile function of the soleus muscle could also result from the complex mechanism of mechanochemical coupling in the actomyosin interaction. For example, the fractional decrease in contractility of rabbit muscle due to specific chemical modification of myosin is less than the fraction of inactivated myosin (Crowder and Cooke, 1984;Root, Cheung et al., 1991). Conversely, inhibition of muscle contraction by inorganic phosphate decreases muscle force without change the fraction of strong-binding myosin heads (Baker, LaConte et al., 1999). This suggests a partial uncoupling between enzymatic and mechanical function of myosin (Murphy, Rock et al., 2001), and/or cooperative interactions within the filament lattice (Root, Cheung et al., 1991;Baker, LaConte et al., 1999;Baker and Thomas, 2000).

\section{Age-related structural changes in muscle protein structure}

Our laboratories initiated studies of the structural basis of age-related changes in muscle contractility by electron paramagnetic resonance (EPR). EPR is a high-resolution spectroscopic method which, in combination with site-specific spin labeling of Cys 707 of myosin in permeabilized muscle fibers, detects changes in the structure of myosin associated with relaxation and isometric contraction of psoas muscle fibers (Ostap, Barnett et al., 1995). In particular, this technique can be used to determine quantitatively the fraction of myosin molecules in the weak- and strong-binding structural states (Thomas, Ramachandran et al., 1995;Baker, LaConte et al., 1999) (Figure 2). EPR studies on the semimembranosus muscle from Fischer $344 \times$ Brown Norway rats and Fischer 344 rats showed that the age-related 24\% $-27 \%$ decrease in the specific tension is associated with a $24 \%-30 \%$ decrease in the fraction of myosin heads in the strong-binding, force-generating structural state (Figure 2)(Lowe, Surek et al., 2001; Thompson, Lowe et al., 2001; Lowe, Warren et al., 2004;Zhong, Lowe et al., 2006). This change in the distribution of structural states of myosin in aged muscle shows that molecular changes in myosin affect contractility by affecting not only biochemical (Prochniewicz, Thomas et al., 2005) but also structural transitions in the actomyosin ATPase cycle. This approach has also proven effective in exploring other causes of muscle degeneration, such as inactivity (Zhong, Lowe et al., 2006) and muscular dystrophy (Lowe, Williams et al., 2006). Weak-to-strong structural transitions within actin also affect muscle function (Prochniewicz and Thomas, 2001;Thomas, Prochniewicz et al., 2002;Prochniewicz, Walseth et al., 2004), but this has not yet been explored as a function of aging.

\section{Age-related oxidative modifications of actin and myosin}

The hypothesis that age-related deterioration of muscle function involves oxidative modification of muscle proteins by reactive oxygen and nitrogen (ROS and NOS) species 
(Stadtman and Berlett, 1997) was suggested by a series of in vitro studies, showing that ROS and NOS such as peroxynitrite, hydroxyl radicals, $\mathrm{H}_{2} \mathrm{O}_{2}$ and nitric oxide inhibit force and induce changes in the Ca-sensitivity of intact and permeabilized muscle (Syrovy and Hodny, 1992;Andrade, Reid et al., 1998;Plant, Lynch et al., 2000;Callahan, She et al., 2001;Lamb and Posterino, 2003; Oh-Ishi, Ueno et al., 2003;Mosoni, Breuille et al., 2004). Studies on in vivo oxidative modifications of actin and myosin focused on few selected markers, such as carbonylation, nitration, formation of HNE (4-hydroxy-2-nonenal) adducts, oxidation of cysteines and glycation. Age-related accumulation of carbonyls was detected in myosin from gastrocnemius muscle of Otsuka Long-Evans Tokushima Fatty rats (Oh-Ishi, Ueno et al., 2003). However, studies on gastrocnemius, EDL, and soleus muscles from male Wistar rats, as well as gastrocnemius muscle of FF344/DuCrj male rats, did not detect any age-dependent increase of total protein carbonyl content (Radak, Takahashi et al., 2002;Mosoni, Breuille et al., 2004). Thus it appears that carbonylation is animal-specific, and that age-related deterioration of contractility is sometimes associated with modification other than carbonylation. It has also been suggested that skeletal muscle has a very efficient system of removal of oxidized contractile proteins to allow uninterrupted muscle function, although the side effects of this system could be loss of muscle mass, contributing to sarcopenia (Mosoni, Breuille et al., 2004).

Recent studies (Thompson, 2006) on the semimembranosus muscle of Fisher 344 rats detected 3-nitrotyrosine and HNE-adducts in actin and in myosin heavy chain, but in both cases the level of modification was similar in young and old muscle. Thus, these modifications are unlikely to explain previously described age-related inhibitory changes in this muscle's contractility and actomyosin interactions (Lowe, Surek et al., 2001;Prochniewicz, Thomas et al., 2005;Zhong, Lowe et al., 2006).

Studies on purified proteins have been more successful. Age-related decrease in cysteine content was detected in myosin from Wistar rats (Srivastava and Kanungo, 1982), from rats of an unspecified strain (Kaldor and Min, 1975), and from semimembranosus muscle of Fischer 344 rats (Prochniewicz, Thomas et al., 2005), but cysteine content of actin was unaffected by age (Prochniewicz, Thomas et al., 2005). The implication of this finding for muscle contractility depends on the still unknown localization of oxidized sites. Oxidation of one or two reactive myosin cysteines (Cys 707 and Cys 696) could result in significant deterioration of muscle contractility (Crowder and Cooke, 1984;Bobkov, Bobkova et al., 1997), but myosin contains about 40 cysteines, and the functional role of the majority is not known.

Another possible explanation of age-related inhibitory effects on myosin is glycation, which has been detected in the skeletal muscle of aged rats (Syrovy and Hodny, 1992). In vitro studies on myosin purified from the soleus muscle of young rats showed that glycation of myosin decreases actin motility (Ramamurthy, Hook et al., 2001) and also decreases $\mathrm{K}^{+}$-activated and actin-activated ATPase activities (Avigad, Kniep et al., 1996). It has been proposed that the mechanism of this functional loss is modification of lysine-rich nucleotide- and actin-binding regions of myosin (Ramamurthy, Hook et al., 2001).

Age-related oxidative modifications of myosin, probably facilitated by a decrease in muscle protein turnover (Balagopal, Rooyackers et al., 1997), provide limited support for oxidative stress as an explanation of age-related deterioration of muscle function. However, conclusive results require determination of the extent and location of oxidized sites, with parallel assessment of functional interactions of myosin.

\section{Age-related changes expression levels of actin and myosin}

Skeletal muscle myosin is a hexamer composed of two heavy chains (MHC) containing regions involved in enzymatic and actin-binding functions of myosin, two regulatory light chains 
(MLC2) and two essential light chains (MLC1 and MLC3), which are implicated in calcium regulation of fiber $\mathrm{V}_{0}$ (Sweeney, Kushmerick et al., 1988), the extent of actin-activated ATPase, and the speed of actin filament sliding in the in vitro motility assay (Wagner, Slater et al., 1979; Lowey, Waller et al., 1993; Timson, 2003). These properties of myosin subunits have inspired studies on age-related changes in the composition and content of MHC and MLC isoforms. Detailed physiological experiments combined with SDS-PAGE analysis of isoform composition of single fibers detected age-related shifts in isoforms that were muscle- and fiberdependent, but these results could not explain changes in muscle contractility (Sugiura, Matoba et al., 1992;Li and Larsson, 1996;Degens, Yu et al., 1998;Thompson and Brown, 1999;Lowe, Surek et al., 2001;D'Antona, Pellegrino et al., 2003;Lowe, Husom et al., 2004). Later studies focused on total MHC and actin content, reporting detected age-related decrease in the MHC but not actin content in the semimembranosus muscle of Fischer 344 rat (Thompson, 2006), but no age-related changes in C57BL mouse soleus and EDL muscle (Moran, Warren et al., 2005). Age-related changes of myosin concentration were also indicated as a major determinant of changes in $\mathrm{P}_{0}$ of human vastus lateralis muscle (D'Antona, Pellegrino et al., 2003). On the other hand, myosin content was unaffected by age in rat soleus muscle (Thompson, 2006), providing further indication of species- and muscle-specific molecular changes in contractile proteins.

Recent progress in mass spectrometry, in combination with two-dimensional gel electrophoresis, has made possible analysis of the age-related changes in the whole muscle proteome. The analysis detected age-related changes in expression of 78 proteins from gastrocnemius muscle of LOU/c/jall rats $(7 \mathrm{mo}$ to $30 \mathrm{mo}$ ), which included lower expression levels for all three myosin light chains, $\alpha$-actin, and cardiac actin. MHC was not detectable by this technology (Piec, 2005). The analysis of proteome from human vastus lateralis muscle detected 52 proteins differently expressed in young and aged subjects, and changes in contractile proteins included down-regulation of MHC-type 1, up-regulation of $\alpha$-actin, and down-regulation of MLC2 (Gelfi, Vigano et al., 2006).

The comparison of results for different muscles shows that changes in the expression levels of contractile proteins are muscle specific. The main consequence of changes in expression levels of contractile proteins is a change in the stoichiometry, which could provide one of the explanations of age-related changes in contractile function.

\section{Ca-regulation of interaction between actin and myosin in aging skeletal muscle}

Ca-regulation of actin-myosin interaction in skeletal muscle occurs via troponin and tropomyosin, and one of the possible consequences of age-related changes in these proteins will be change in Ca-regulation of muscle contractility. This possibility was tested in the semimembranosus muscle of rat, but 30\% age-related decrease in force was not accompanied by significant changes in its Ca-sensitivity (Lowe, Thomas et al., 2002). On the other hand, proteomic studies on gastrocnemius and vastus lateralis muscle of rat and human, respectively, detected age-related changes in the expression levels of troponin $\mathrm{T}$ and of $\alpha$-tropomyosin, but these muscle were not assessed for age-related changes in Ca-sensitivity of contraction (Piec, 2005; Gelfi, Vigano et al., 2006). Thus, the question of the role of age-related changes in troponin and tropomyosin in contractility of skeletal muscle requires further studies.

\section{Summary and perspective}

Physiological studies have detected age-related deterioration of contractility of permeabilized muscle fibers, dependent on the animal, age, and muscle. Structural analysis, using site-directed spin labeling, indicates directly that structural changes in myosin occur with aging. 
Biochemical and structural studies on myofibrils and isolated actin and myosin have reported age-related, muscle-specific molecular changes in myosin and actin, which are most likely due to oxidative modifications. These qualitative changes are sometimes accompanied by musclespecific changes in the stoichiometry of contractile proteins. In view of the muscle-specificity of age-related changes, understanding of the molecular basis of physiological changes requires a multidisciplinary experimental approach, in which a specific muscle is studied using a wide range of physiological, biochemical, structural and chemical techniques.

\section{Acknowledgements}

We thank Dawn Lowe, Deborah Ferrington, and Daniel Spakowicz for many useful discussions. This work was supported by NIH grants to DDT (AR27906 and AG26160) and LT (AG17768 and AG21626).

\section{References}

Ajtai K, Peyser YM, Park S, Burghardt TP, Muhlrad A. Trinitrophenylated reactive lysine residue in myosin detects lever arm movement during the consecutive steps of ATP hydrolysis. Biochemistry 1999;38:6428-6440. [PubMed: 10350461]

Andrade FH, Reid MB, Allen DG, Westerblad H. Effect of nitric oxide on single skeletal muscle fibres from the mouse. J Physiol 1998;509(Pt 2):577-586. [PubMed: 9575305]

Avigad G, Kniep A, Bailin G. Reaction of rabbit skeletal myosin with D-glucose 6-phosphate. Biochem Mol Biol Int 1996;40:273-284. [PubMed: 8896749]

Baker JE, LaConte LE, Brust-Mascher II, Thomas DD. Mechanochemical coupling in spin-labeled, active, isometric muscle. Biophys J 1999;77:2657-2664. [PubMed: 10545366]

Baker JE, Thomas DD. Thermodynamics and kinetics of a molecular motor ensemble. Biophys J 2000;79:1731-1736. [PubMed: 11023881]

Balagopal P, Rooyackers OE, Adey DB, Ades PA, Nair KS. Effects of aging on in vivo synthesis of skeletal muscle myosin heavy-chain and sarcoplasmic protein in humans. Am J Physiol 1997;273:E790-800. [PubMed: 9357810]

Barany M. ATPase activity of myosin correlated with speed of muscle shortening. J Gen Physiol 1967;50 (Suppl):197-218. [PubMed: 4227924]

Bertrand R, Derancourt J, Kassab R. Production and properties of skeletal myosin subfragment 1 selectively labeled with fluorescein at lysine-553 proximal to the strong actin-binding site. Biochemistry 1995;34:9500-9507. [PubMed: 7626619]

Bobkov AA, Bobkova EA, Homsher E, Reisler E. Activation of regulated actin by SH1-modified myosin subfragment 1. Biochemistry 1997;36:7733-7738. [PubMed: 9201914]

Bobkova EA, Bobkov AA, Levitsky DI, Reisler E. Effects of SH1 and SH2 modifications on myosin: similarities and differences. Biophys J 1999;76:1001-1007. [PubMed: 9916031]

Callahan LA, She ZW, Nosek TM. Superoxide, hydroxyl radical, and hydrogen peroxide effects on single-diaphragm fiber contractile apparatus. J Appl Physiol 2001;90:45-54. [PubMed: 11133892]

Crowder MS, Cooke R. The effect of myosin sulphydryl modification on the mechanics of fibre contraction. J Muscle Res Cell Motil 1984;5:131-146. [PubMed: 6144694]

D'Antona G, Pellegrino MA, Adami R, Rossi R, Carlizzi CN, Canepari M, Saltin B, Bottinelli R. The effect of ageing and immobilization on structure and function of human skeletal muscle fibres. $\mathrm{J}$ Physiol 2003;552:499-511. [PubMed: 14561832]

Degens H, Yu F, Li X, Larsson L. Effects of age and gender on shortening velocity and myosin isoforms in single rat muscle fibres. Acta Physiol Scand 1998;163:33-40. [PubMed: 9648621]

Florini JR, Ewton DZ. Skeletal muscle fiber types and myosin ATPase activity do not change with age or growth hormone administration. J Gerontol 1989;44:B110-117. [PubMed: 2527906]

Gelfi C, Vigano A, Ripamonti M, Pontoglio A, Begum S, Pellegrino MA, Grassi B, Bottinelli R, Wait $\mathrm{R}$, Cerretelli P. The human muscle proteome in aging. J Proteome Res 2006;5:1344-1353. [PubMed: 16739986]

Hook P, Li X, Sleep J, Hughes S, Larsson L. In vitro motility speed of slow myosin extracted from single soleus fibres from young and old rats. J Physiol 1999;520(Pt 2):463-471. [PubMed: 10523415]

Exp Gerontol. Author manuscript; available in PMC 2008 October 1. 
Hook P, Sriramoju V, Larsson L. Effects of aging on actin sliding speed on myosin from single skeletal muscle cells of mice, rats, and humans. Am J Physiol Cell Physiol 2001;280:C782-788. [PubMed: 11245594]

Ingalls CP, Warren GL, Armstrong RB. Dissociation of force production from MHC and actin contents in muscles injured by eccentric contractions. J Muscle Res Cell Motil 1998;19:215-224. [PubMed: 9583362]

Kaldor G, Min BK. Enzymatic studies on the skeletal myosin A and actomyosin of aging rats. Fed Proc 1975;34:191-194. [PubMed: 123207]

Krivickas LS, Suh D, Wilkins J, Hughes VA, Roubenoff R, Frontera WR. Age- and gender-related differences in maximum shortening velocity of skeletal muscle fibers. Am J Phys Med Rehabil 2001;80:447-455. [PubMed: 11399006]quiz 456-447

Lamb GD, Posterino GS. Effects of oxidation and reduction on contractile function in skeletal muscle fibres of the rat. J Physiol 2003;546:149-163. [PubMed: 12509485]

Larsson L, Li X, Frontera WR. Effects of aging on shortening velocity and myosin isoform composition in single human skeletal muscle cells. Am J Physiol 1997;272:C638-649. [PubMed: 9124308]

Li X, Larsson L. Maximum shortening velocity and myosin isoforms in single muscle fibers from young and old rats. Am J Physiol 1996;270:C352-360. [PubMed: 8772463]

Lowe DA, Husom AD, Ferrington DA, Thompson LV. Myofibrillar myosin ATPase activity in hindlimb muscles from young and aged rats. Mech Ageing Dev 2004;125:619-627. [PubMed: 15491680]

Lowe DA, Surek JT, Thomas DD, Thompson LV. Electron paramagnetic resonance reveals age-related myosin structural changes in rat skeletal muscle fibers. Am J Physiol Cell Physiol 2001;280:C540547. [PubMed: 11171573]

Lowe DA, Thomas DD, Thompson LV. Force generation, but not myosin ATPase activity, declines with age in rat muscle fibers. Am J Physiol Cell Physiol 2002;283:C187-192. [PubMed: 12055087]

Lowe DA, Warren GL, Snow LM, Thompson LV, Thomas DD. Muscle activity and aging affect myosin structural distribution and force generation in rat fibers. J Appl Physiol 2004;96:498-506. [PubMed: 14514706]

Lowe DA, Williams BO, Thomas DD, Grange RW. Molecular and cellular contractile dysfunction of dystrophic muscle from young mice. Muscle Nerve 2006;34:92-100. [PubMed: 16634063]

Lowey S, Waller GS, Trybus KM. Function of skeletal muscle myosin heavy and light chain isoforms by an in vitro motility assay. J Biol Chem 1993;268:20414-20418. [PubMed: 8376398]

Marston SB, Taylor EW. Comparison of the myosin and actomyosin ATPase mechanisms of the four types of vertebrate muscles. J Mol Biol 1980;139:573-600. [PubMed: 6447797]

Moran AL, Warren GL, Lowe DA. Soleus and EDL muscle contractility across the lifespan of female C57BL/6 mice. Exp Gerontol 2005;40:966-975. [PubMed: 16243468]

Mosoni L, Breuille D, Buffiere C, Obled C, Mirand PP. Age-related changes in glutathione availability and skeletal muscle carbonyl content in healthy rats. Exp Gerontol 2004;39:203-210. [PubMed: 15036413]

Murphy CT, Rock RS, Spudich JA. A myosin II mutation uncouples ATPase activity from motility and shortens step size. Nat Cell Biol 2001;3:311-315. [PubMed: 11231583]

Oh-Ishi M, Ueno T, Maeda T. Proteomic method detects oxidatively induced protein carbonyls in muscles of a diabetes model Otsuka Long-Evans Tokushima Fatty (OLETF) rat. Free Radic Biol Med 2003;34:11-22. [PubMed: 12498975]

Ostap EM, Barnett VA, Thomas DD. Resolution of three structural states of spin-labeled myosin in contracting muscle. Biophys J 1995;69:177-188. [PubMed: 7669895]

Piec I, Listrat A, Alliot J, Chambon C, Taylor RG, Bechet D. Differential proteome analysis of aging in rat skeletal muscle. The FASEB Journal published online. 2005

Plant DR, Lynch GS, Williams DA. Hydrogen peroxide modulates Ca2+-activation of single permeabilized fibres from fast- and slow-twitch skeletal muscles of rats. J Muscle Res Cell Motil 2000;21:747-752. [PubMed: 11392556]

Prochniewicz E, Thomas DD. Site-specific mutations in the myosin binding sites of actin affect structural transitions that control myosin binding. Biochemistry 2001;40:13933-13940. [PubMed: 11705383] 
Prochniewicz E, Thomas DD, Thompson LV. Age-related decline in actomyosin function. J Gerontol A Biol Sci Med Sci 2005;60:425-431. [PubMed: 15933379]

Prochniewicz E, Walseth TF, Thomas DD. Structural dynamics of actin during active interaction with myosin: different effects of weakly and strongly bound myosin heads. Biochemistry 2004;43:1064210652. [PubMed: 15311925]

Radak Z, Takahashi R, Kumiyama A, Nakamoto H, Ohno H, Ookawara T, Goto S. Effect of aging and late onset dietary restriction on antioxidant enzymes and proteasome activities, and protein carbonylation of rat skeletal muscle and tendon. Exp Gerontol 2002;37:1423-1430. [PubMed: 12559411]

Ramamurthy B, Hook P, Jones AD, Larsson L. Changes in myosin structure and function in response to glycation. Faseb J 2001;15:2415-2422. [PubMed: 11689466]

Reisler E. Sulfhydryl modification and labeling of myosin. Methods Enzymol 1982;85(Pt B):84-93. [PubMed: 6214695]

Root DD, Cheung P, Reisler E. Catalytic cooperativity induced by SH1 labeling of myosin filaments. Biochemistry 1991;30:286-294. [PubMed: 1824816]

Srivastava SK, Kanungo MS. Aging modulates some properties of skeletal myosin ATPase of rat. Biochem Med 1982;28:266-272. [PubMed: 6219669]

Stadtman ER, Berlett BS. Reactive oxygen-mediated protein oxidation in aging and disease. Chem Res Toxicol 1997;10:485-494. [PubMed: 9168245]

Sugiura T, Matoba H, Miyata H, Kawai Y, Murakami N. Myosin heavy chain isoform transition in ageing fast and slow muscles of the rat. Acta Physiol Scand 1992;144:419-423. [PubMed: 1605043]

Sweeney HL, Kushmerick MJ, Mabuchi K, Sreter FA, Gergely J. Myosin alkali light chain and heavy chain variations correlate with altered shortening velocity of isolated skeletal muscle fibers. J Biol Chem 1988;263:9034-9039. [PubMed: 3379059]

Syrovy I, Gutmann E. Changes in speed of contraction and ATPase activity in striated muscle during old age. Exp Gerontol 1970;5:31-35. [PubMed: 4245936]

Syrovy I, Hodny Z. Non-enzymatic glycosylation of myosin: effects of diabetes and ageing. Gen Physiol Biophys 1992;11:301-307. [PubMed: 1426977]

Takashi R, Duke J, Ue K, Morales MF. Defining the "fast-reacting" thiols of myosin by reaction with 1, 5 IAEDANS. Arch Biochem Biophys 1976;175:279-283. [PubMed: 133635]

Thomas DD, Prochniewicz E, Roopnarine O. Changes in actin and myosin structural dynamics due to their weak and strong interactions. Results Probl Cell Differ 2002;36:7-19. [PubMed: 11892285]

Thomas DD, Ramachandran S, Roopnarine O, Hayden DW, Ostap EM. The mechanism of force generation in myosin: a disorder-to-order transition, coupled to internal structural changes. Biophys J 1995;68:135S-141S. [PubMed: 7787056]

Thompson LV, Brown M. Age-related changes in contractile properties of single skeletal fibers from the soleus muscle. J Appl Physiol 1999;86:881-886. [PubMed: 10066700]

Thompson LV, Durand D, Fugere NA, Ferrington DA. Myosin and actin expression and oxidation in aging muscle. J. Appl. Physiol. 2006epub

Thompson LV, Lowe DA, Ferrington DA, Thomas DD. Electron paramagnetic resonance: a highresolution tool for muscle physiology. Exerc Sport Sci Rev 2001;29:3-6. [PubMed: 11210444]

Timson DJ. Fine tuning the myosin motor: the role of the essential light chain in striated muscle myosin. Biochimie 2003;85:639-645. [PubMed: 14505818]

Wagner PD, Slater CS, Pope B, Weeds AG. Studies on the actin activation of myosin subfragment-1 isoezymes and the role of myosin light chains. Eur J Biochem 1979;99:385-394. [PubMed: 159176]

Yates LD, Greaser ML. Quantitative determination of myosin and actin in rabbit skeletal muscle. J Mol Biol 1983;168:123-141. [PubMed: 6876172]

Zhong S, Lowe DA, Thompson LV. Effects of hindlimb unweighting and aging on rat semimembranosus muscle and myosin. J Appl Physiol 2006;101:873-880. [PubMed: 16690785] 


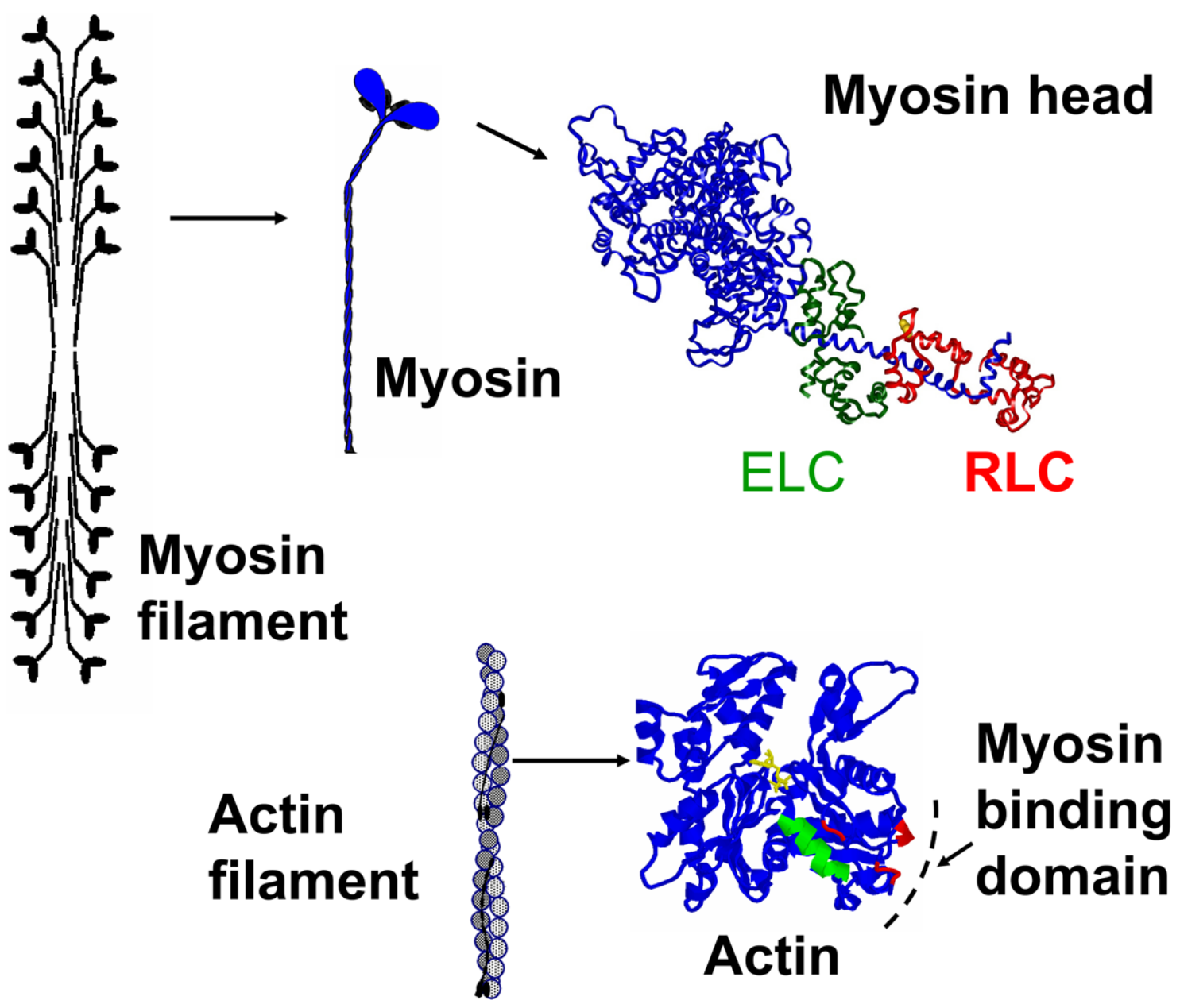

Figure 1.

Structure of skeletal muscle actin monomer and myosin head. 

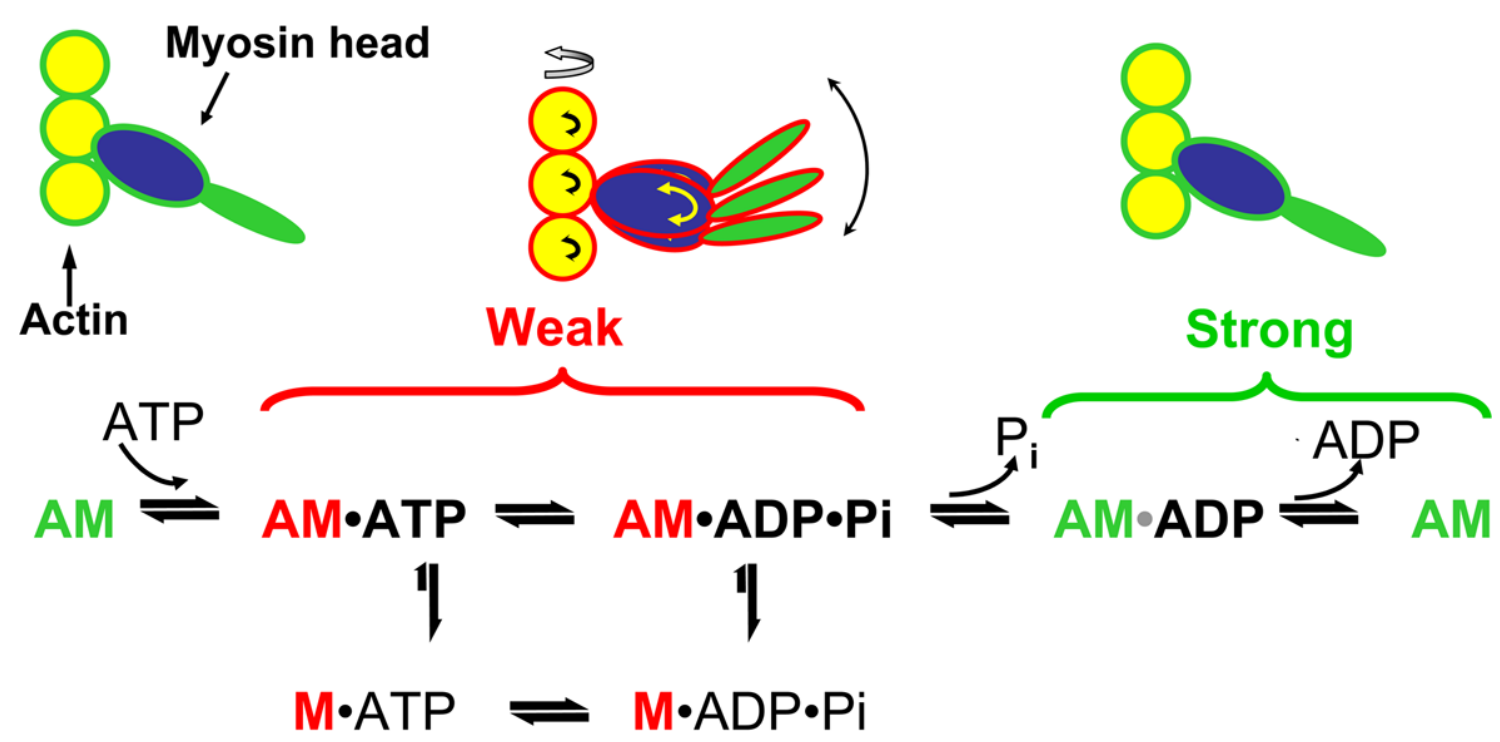

Figure 2.

Schematic of structural and biochemical steps of ATP hydrolysis by myosin in the presence of actin (actomyosin ATPase cycle). Both catalytic (blue) and light chain domains (green) of myosin are disordered in weak binding state (indicated by arrows) and ordered in the strong binding state. 


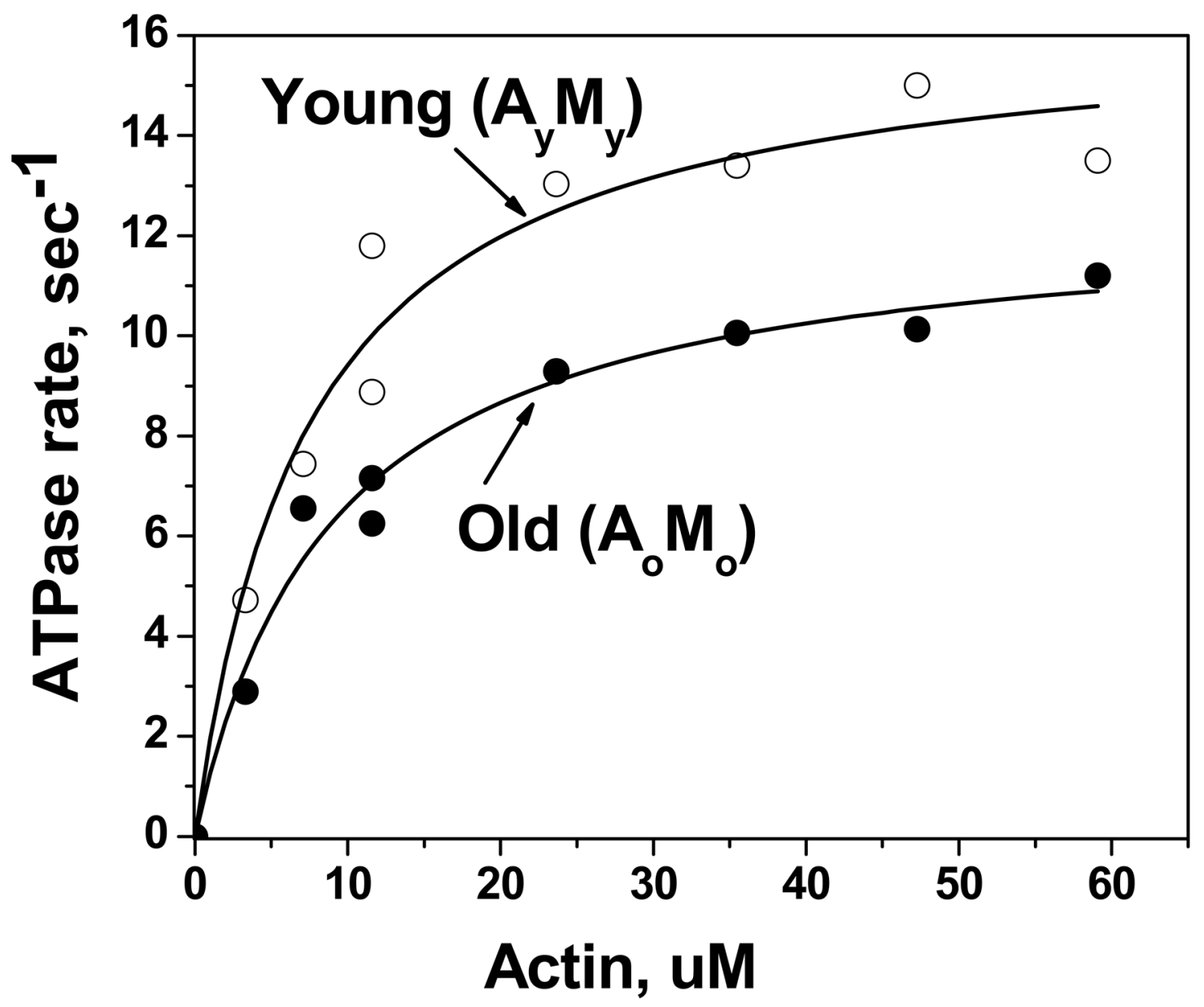

Figure 3.

Representative data used to determine Vmax and Km. oyoung actin and young HMM; • old actin and old HMM [5]. 

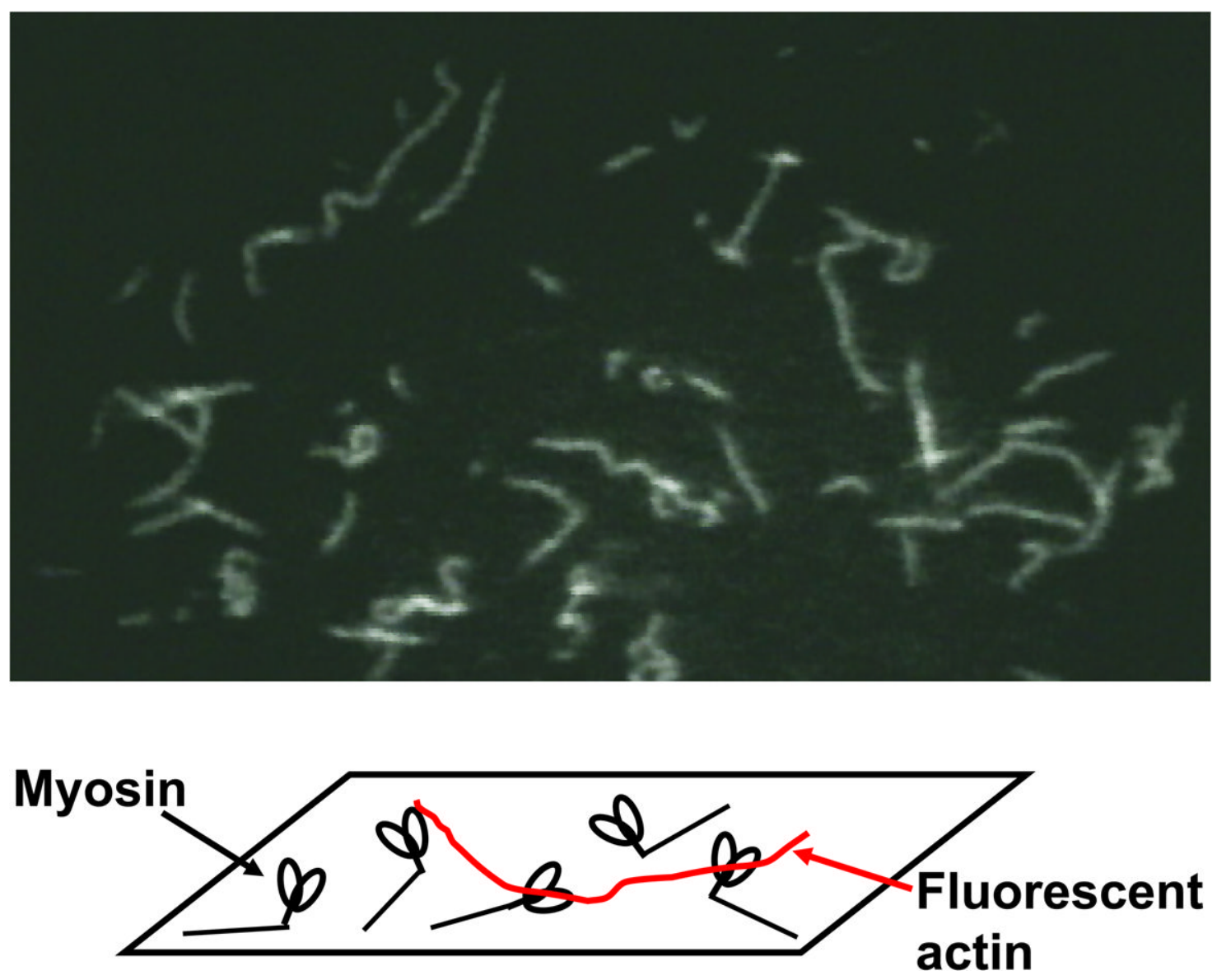

Figure 4.

Schematic of the in vitro motility assay and a microscopic view of sliding actin filaments. 
Table 1

Age-related changes in specific force and unloaded shortening velocity of permeabilized muscle

\begin{tabular}{|c|c|c|c|c|}
\hline Source & Muscle & $\begin{array}{l}P_{0} \\
\text { Old/Young }\end{array}$ & $\begin{array}{l}V_{0} \\
\text { Old/Young }\end{array}$ & Ref \\
\hline Wistar rats & EDL, IIxb & & & (Li and Larsson, 1996) \\
\hline \multicolumn{5}{|l|}{$\begin{array}{l}\text { Y: } 3-6 \mathrm{mo} \\
\mathrm{O}: 20-24 \mathrm{mo}\end{array}$} \\
\hline & Soleus & $0.91, \mathrm{p}<0.05$ & $0.53, \mathrm{p}<0.01$ & \\
\hline Wistar rats & EDL & $1.13, p<0.05$ & 0.97 & $\begin{array}{l}\text { (Degens, Yu et al., } \\
\text { 1998), }\end{array}$ \\
\hline Y: $3-6$ mo & $\mathrm{N}=39$ to 48 & & & \\
\hline O: $22-24 \mathrm{mo}$ & $\begin{array}{l}\text { Soleus } \\
\mathrm{N}=19 \text { to } 78\end{array}$ & 0.89 & $0.54, \mathrm{p}<0.05$ & \\
\hline Fischer 344 & Soleus & $0.53, \mathrm{p} \leq 0.05$ & $0.61, \mathrm{p} \leq 0.05$ & $\begin{array}{l}\text { (Thompson and Brown, } \\
\text { 1999) }\end{array}$ \\
\hline $\begin{array}{l}\text { Brown Norway rats. Y: } 12 \text { mo } \\
\text { O: } 37 \text { mo }\end{array}$ & $\mathrm{N}=19$ to 27 & & & \\
\hline Fischer 344 & Semimembrano sus & $0.84, p=0.02$ & & $\begin{array}{l}\text { (Lowe, Surek et al., } \\
\text { 2001) }\end{array}$ \\
\hline $\begin{array}{l}\text { Brown Norway rats Y: } 8-12 \mathrm{mo} \\
\text { O: } 32-36 \mathrm{mo}\end{array}$ & $\mathrm{N}=30$ to $33 \mathrm{~s}$ & & & \\
\hline Fischer 344 rats & Semimembrano sus & 0.77 & 0.78 & $\begin{array}{l}\text { (Prochniewicz, Thomas } \\
\text { et al., 2005) }\end{array}$ \\
\hline $\begin{array}{l}\text { Y: } 4-12 \mathrm{mo} \\
\mathrm{O}: 27-35 \mathrm{mo}\end{array}$ & $\mathrm{N}=3$ & & & \\
\hline Fischer 344 & Semimembrano sus & $0.72(\mathrm{p}<0.001)$ & & $\begin{array}{l}\text { (Zhong, Lowe et al., } \\
\text { 2006) }\end{array}$ \\
\hline $\begin{array}{l}\text { Brown Norway rats } \\
\text { Y: } 6 \mathrm{mo} \\
\text { O: } 28 \mathrm{mo}\end{array}$ & & & & \\
\hline $\begin{array}{l}\text { Human } \\
\text { Hum }\end{array}$ & Vastus Lateralis & & $0.83, \mathrm{p}<0.001$ & $\begin{array}{l}\text { (Krivickas, Suh et al., } \\
\text { 2001) }\end{array}$ \\
\hline $\begin{array}{l}Y: 36.5 \pm 3 \text { y } \\
\text { O: } 74.4 \pm 6\end{array}$ & $\begin{array}{l}\text { Type IIa } \\
\mathrm{N}=82 \text { to } 92\end{array}$ & & & \\
\hline Human, men & Vastus Lateralis & & & \\
\hline Y: 25-31 y & Type IIa & $0.72, \mathrm{p}<0.001$ & $0.85, \mathrm{p}<0.001$ & $\begin{array}{l}\text { (Larsson, Li et al., } \\
\text { 1997) }\end{array}$ \\
\hline O: $73-81$ y & $\mathrm{N}=41$ to 47 & & & \\
\hline Human & Vastus lateralis & & & $\begin{array}{l}\text { (D'Antona, Pellegrino et } \\
\text { al., 2003) }\end{array}$ \\
\hline $\begin{array}{l}\text { Y: } 30.2 \pm 2.2 \mathrm{y} \\
\text { O: } 72.7 \pm 2.3 \mathrm{y}\end{array}$ & $\begin{array}{l}\text { Type IIa } \\
\mathrm{N}=5 \text { to } 143\end{array}$ & $0.89, \mathrm{p}<0.05$ & $0.87, \mathrm{p}<0.05$ & \\
\hline
\end{tabular}

$\mathrm{N}$ : number of fibers used in experiments; $\mathrm{P}_{0}$ : specific force; $\mathrm{V}_{0}$ : unloaded shortening velocity; Old/Young: calculated ratio of the average values reported in the referred papers. 
Prochniewicz et al.

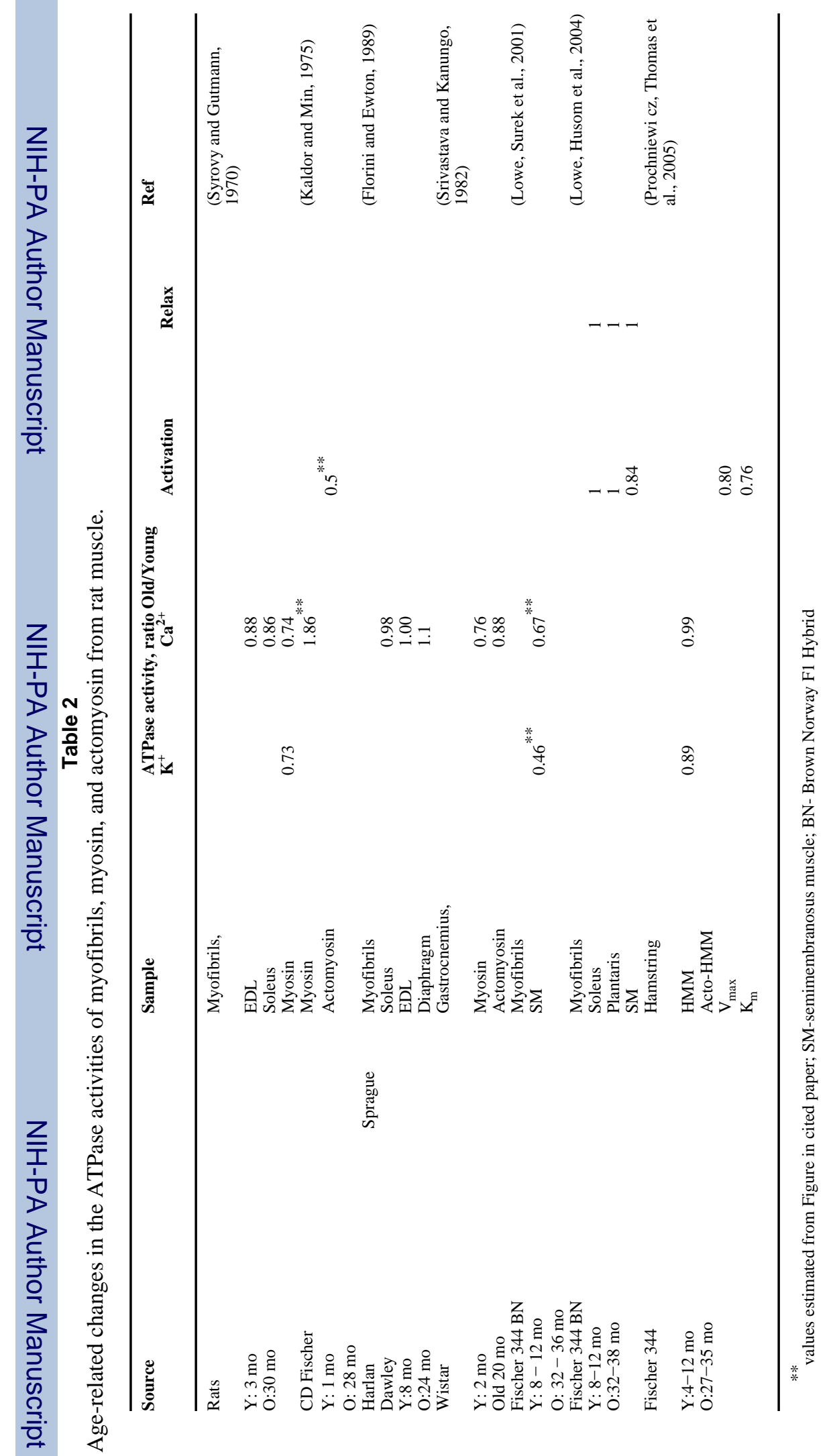

Exp Gerontol. Author manuscript; available in PMC 2008 October 1. 